Social Inquiry: Journal of Social Science Research

2019, Vol. 1, No. 1, pp. 1-7

DOI: https://doi.org/10.3126/sijssr.v1i1.26912

\title{
Editorial
}

\section{A Dialogue on Social Inquiry: Expanding Our Understanding of Sociological Thinking}

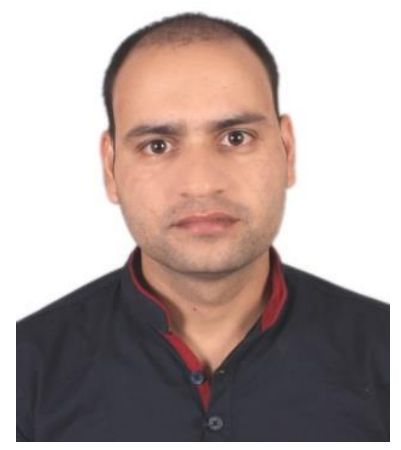

Rebat Kumar Dhakal

School of Education, Kathmandu University, Lalitpur, Nepal

Email: rebat@kusoed.edu.np

0000-0003-4009-7268

\section{Highlights}

- Social inquiry is much more than the study of society. It further excavates historical facts, critically reflects on everyday happenings, and envisions the future we wish to create.

The intent of initiating this dialogue on social inquiry is two-fold: a) to offer a sociological perspective (i.e. 'thinking sociologically'), and b) to expand our understanding of sociological thinking.

Sociological thinking can be developed by examining the periphery of the core.

Context matters in understanding any phenomenon under the sociological microscope.

- Sociological thinking allows many different viewpoints to coexist within a larger structure and that it respects pluralism. 
Sociological thinking is about developing or providing a perspective to examine social nuances.

Sociological thinking should act as a means for social transformation.

Social inquiry serves as a methodology for the social sciences and humanities. It deals with the philosophy of social science and the workings of the social world - giving a way for understanding both the biosphere and the sociosphere.

\section{Opening Thoughts}

In everyday language, social inquiry may be understood to mean 'asking questions to gain information on social issues, events, and processes' that affect, or are influenced by, human actions and interactions. In this light, social inquiry focuses on raising important questions, in want of elucidations, related to social institutions, policies, processes and individuals. In the context of instructional approach, New Zealand's Ministry of Education (2008) defines social inquiry as "an integrated process for examining social issues, ideas and themes" (p. 2). As such, social inquiry seeks answers to our everyday questions that surround us - about somebody/something or nobody/nothing.

Until recently, scholarly discourse on sociology in general has shaped sociological thinking into disciplinary specialism, producing sociologists who are able to talk only to other sociologists and social scientists. However, social inquiry adopts Mills' (1959) idea of 'sociological imagination' which underscores that sociology should contribute to resolving the most significant and urgent questions of our time. In this sense, social inquiry is much more than the study of society. It means, social inquiry further excavates historical facts, critically reflects on everyday happenings, and envisions the future we wish to create. The notion of 'sociological imagination' postulated by Mills helps us understand this better. For Mills, sociology not only helps us to analyse current and existing patterns of social life, but it also helps us to see some of the possible futures open to us. Moreover, through sociological imagination, we can see not only what is real, but also what could become real should we desire to make it that way. Thereby, a sociological inquiry may seek sustainable solutions to our ever increasing societal challenges. Therefore, it focuses on "the structure and organisation of society and how this relates to social problems and individual lives" (Shildrick \& Rucell, 2015, p. 1). Above all, the intent of initiating this dialogue on social inquiry is two-fold: a) to offer a sociological perspective (i.e. 'thinking sociologically'), and b) to expand our understanding of sociological thinking.

\section{Thinking Sociologically}

Sociological thinking refers to a person's rational cum logical ability that allows them to reflect a little on how personal relationships fit into a wider social system. It fosters critical and contextual thoughtfulness that allows one to relate their personal experiences to others and others' experiences to themselves and also fit them into a bigger 
societal context. As such, a sociological perspective accomplishes this reflection through disclosing choices and patterns individuals take in regard to their social relationships and revealing their influences on different dimensions of society (Browne, 2015). Therefore, dynamic societal contexts play an overriding role in understanding social realities. Moreover, 'reality' and 'knowledge' can only be examined in light of their "social relativity" (Berger \& Luckmann, 1966, p. 13).

Interpersonal relationships across situations and experiences in social contexts create sociological knowledge (Cronin \& Mandich, 2015). In this sense, a sociological perspective can be understood as "a way of seeing the world through the evaluation of social structures and force" (Cole, 2019). Therefore, sociological thinking encourages one to see reality as socially constructed and that the sociology of knowledge needs to critically examine the process in which this occurs (Berger \& Luckmann, 1966, p. 13). Therefore, sociological thinking fosters critical examination of the software (culture, beliefs, values ...) and hardware (social structures, status, institutions ...) of society deeply rooted in the everyday consciousness of people, and that it provides a framework that can be used to characterize such consciousness.

Sociological thinking can be developed by examining the periphery of the core. When you are invited by a friend for a cup of tea, the sociological meaning of 'having a cup of tea', especially in Nepal and other South Asian countries, is beyond what you drink; it's often and actually about the meeting and chatting, which serves as an occasion for social interaction. The very teaing [having tea] or chiya-guff [chit-chat at teaing] becomes an informal space for rapport, relationship and trust building, which forms a basis for getting things done later. In fact, it serves as an informal decision-making space. Thus, context matters in understanding any individual or phenomenon under the sociological microscope. Since the context of Nepal has been raised, it is important to retrospect into our comparatively young discourse of social sciences, especially sociology/anthropology. Though this subfield is rich in research, it has continuously been initiated by western researchers (Hachhethu, 2002; Subedi \& Uprety, 2014). This calls for native researchers to be serious in developing local knowledges and understandings (Dhakal, 2014, 2016; Parajuli, 2014). Here, it is relevant to quote an example from Berger and Luckmann (1966):

What is 'real' to a Tibetan monk may not be 'real' to an American businessman. The 'knowledge' of the criminal differs from the 'knowledge' of the criminologist. It follows that specific agglomerations of 'reality' and 'knowledge' pertain to specific social contexts, and that these relationships will have to be included in an adequate sociological analysis of these contexts. (p. 15)

Therefore, it is important to note that sociological thinking allows many different viewpoints to coexist within a larger structure and that it respects pluralism, which "offers an account of social interaction understood as an interplay of conflicting and competing 
positions that cannot be seamlessly reduced to one another, ranked in one single order permanently, or reduced to a single institutional arrangement" (Yumatle, 2015, p. 1).

A sociological perspective fosters critical thinking, poses analytical questions, and pursues solutions (Cole, 2019). Therefore, a sociological approach calls for "various intuitive, embodied, creative, aesthetic and spiritual modalities to delve beyond the conventional givens of the Western tradition's epistemic processes" (Bussey, 2018, p. 221). To take an out-of-context example, the "CV of Failures" published by Princeton Professor Johannes Haushofer offers a perspective - which he claims received way more attention than his entire body of academic work (Haushofer, 2016). Therefore, sociological thinking is about developing or providing a perspective to examine social nuances.

\section{Expanding Our Understanding of Sociological Thinking}

Much of sociological scholarship still relies on a largely pre-given vertical hierarchy which fixes things on just two scales, with micro-level phenomena at the bottom and large macro-scale forces at the top (Pyyhtinen, 2016, p. 2). In sociology, the individual aspects of social life are known as the "micro," and the large-scale groups, relationships, and trends that make up society are known as the "macro" (Cole, 2019). However, in a complex social dynamics, looking for relationships between the micro and marco to recommend ways to address the trends and problems that arise in society is not adequate. Therefore, sociological thought is in need of remoulding.

These days, canonical prescriptions about the proper way of making science are increasingly facing strong headwinds (Jessor, 1996, p. 3). In fact, there is no 'proper way' of doing research, and therefore a more allembracing perspective in pursuit of knowledge and understanding is gaining currency. Social inquiry is geared towards this direction. In fact, social inquiry is an approach to fostering social dialogue that stimulates interaction between social actors, which ultimately contributes to inclusive growth and social justice. With changing nature of lifestyle and relationships, expansion is implied on social science concepts to be inclusive and of relevance to the humans and the society. Yet, we, as social inquirers, are to be critically aware that relativity prevails while expanding our understanding of 'others' and 'ourselves' and the interrelationships.

As highlighted above, social inquirers now increasingly tend to believe that there is a plurality of standpoints of actors and institutions. For Béteille (2009), a sociological approach presents us plural standpoints:

...there is no one unique or privileged standpoint in the study of society and culture. Even within the same society there generally is a plurality of standpoints, varying with religion, class, gender or moral and intellectual predilection, and besides different outsiders may view the same society from different standpoints. (p. 210) 
Sociologists are blamed to have turned into disciplinary specialists who are able to talk only to other sociologists and social scientists. In Mills' (1959) vision, by contrast, sociology should be of relevance to both public issues and to personal troubles and experiences. For Mills (1959), "The educational and political role of social science in a democracy is to help cultivate and sustain publics and individuals that are able to develop, to live with, and to act upon adequate definitions of personal and social realities" (p. 192). One key aspect that the paper focuses is Mills' vision that sociological imagination should include a sense of social responsibility. This aspect of developing a sense of social responsibility by social inquirer can be best learned through a combination of experience and academic knowledge (Hironimus-Wendt \& Wallace, 2009, p. 76). It makes us aware that we are at least partially responsible for the conditions found in our social environments. In this context, "individual's behaviour needs to be understood in terms of that person's social context is dismissed as "letting the individual off' of taking personal responsibility for their actions" (Little, 2013, p. 6). Therefore, sociological thinking should act as a means for social transformation.

In this context of sociology as praxis (i.e., practical intervention), the "promise" of social science education becomes clear (Hironimus-Wendt \& Wallace, 2009, p. 85). According to Colby Ehrlich, Beaumont, and Stephens (2003), "The civically responsible individual recognizes himself or herself as a member of a larger social fabric and therefore considers social problems to be at least partly his or her own" (p. 16). Social responsibility implies an "affective sense of connection to others in the community (empathy), and more importantly, it implies a sense of responsibility for others" (Hironimus-Wendt \& Wallace, 2009, p. 78). Sociological thinking is therefore called upon to play a major role in the movement to restructure the life of society and to transform our society. Adopting the transformative strand of sociology, sociological thinking should "provide a scientific foundation for current and long-term plans for developing the social sphere, and for the scientific monitoring of the implementation of change" (Soviet Sociology, 1988, p. 7). It is my contention, then, that this understanding of the transformative field of sociology differs from what has loosely been meant by this discipline.

Akin to the transformative path of sociological imagination, Flyvbjerg (2001) underscores that we need social science that matters. In his words,

...We may transform social science to an activity done in public for the public, sometimes to clarify, sometimes to intervene, sometimes to generate new perspectives, and always to serve as eyes and ears in our ongoing efforts at understanding the present and deliberating about the future. (p. 116)

Moving on, Flyvbjerg (2001) quotes Aristotle and endorses that the most important task of social inquiry is to develop society's value-rationality since social development based on instrumental rationality alone is not sustainable (p. 53). Therefore, it is on the shoulders of the 
sociological thinkers and social inquirers to adopt value-rationality vis-a'-vis its scientific and technical rationality. For the reason of 'conflict of interest', I write the first part of the next sentence implicitly - not citing any specific policy. We have witnessed that some social/institutional policies have gone too far (the violators of policies may not be wrong, instead policies need modifications) and thus our inquiry should present an alternative perspective - whether we use a fork as a tool or as a weapon. Here, I would emphasize that I have no reservations whatsoever about the importance of these two sets of rationalities. However, on closer inspection, I regard it as unfortunate that technical rationality has dominated the sociology of knowledge so far.

\section{Closing Remarks}

Embracing an African proverb "We make our path by walking it", I invite social inquirers, through this think-piece, to adopt social inquiry as a method more ardently than before, also as an alternative to positivist social science, for both obtaining data on some social phenomena and also an interpretation of them. It helps deepen our understanding of the basic ideas and arguments that inform contemporary sociological thinking. I further reaffirm that it serves as a methodology for the social sciences and humanities to apply reflective and systematic thought to the social world. It deals with the philosophy of social science and the workings of the social world - giving a way for understanding both the biosphere and the sociosphere. This journal promotes similar discourse and thus it is up to us, as authors and readers, how we situate social inquiry in a contemporary scholarly milieu.

\section{Acknowledgments}

I, on behalf of the Editorial Board, would like to extend a big 'thank you' to the contributing authors for choosing to submit their work for this exciting project. I also thank the numerous anonymous referees who devoted their time and expertise to provide valuable feedback to the contributors. Finally, I also thank many other researchers in the field who submitted inspiring and thought-provoking research, yet unfortunately could not be contained within this issue.

\section{References}

Berger, P. L., \& Luckmann, T. (1966). The social construction of reality - A treatise in the sociology of knowledge. London, England: Penguin Books.

Béteille, A. (2009). Sociology and ideology. Sociological Bulletin, 58(2), 196-211.

Browne, C. (2015). Change is central to sociology. In G. Bammer (Ed.), Change: Combining analytic approaches with street wisdom (pp. 55-79). Acton, Australia: Australian National University Press.

Bussey, M. (2018). Afterword: Beyond a materialist sociology. In A. K. Giri (Ed.), Beyond sociology (pp. 221-224). Gateway East, Singapore: Springer Nature.

Colby, A., Ehrlich, T., Beaumont, E., \& Stephens, J. (2003). Educating citizens: Preparing America's undergraduates for lives of moral and civic responsibility. Menlo Park, CA: Carnegie Foundation for the Advancement of Teaching / Jossey-Bass. 
Cole, N. L. (2019, October 19).

Understanding the sociological perspective - How sociologists see the world. Retrieved from https://www.thoughtco.com/sociological -perspective-3026642

Cronin, A., \& Mandich, M. B. (Eds.). (2015). Human development and performance throughout the lifespan (2nd ed.). Boston, MA: Cengage Learning.

Dhakal, R. (2014). Reengineering education and reimagining rural transformation. Journal of Education and Research, 4(2), 1-6.

Dhakal, R. K. (2016). Making rural transformation happen: Turning stumbling blocks into road to success. Journal of Education and Research, 5(2)/6(1), 1-8.

Flyvbjerg, B. (2001). Making social science matter - Why social inquiry fails and how it can succeed again (Trans. S. Sampson). Cambridge, England: Cambridge University Press.

Hachhethu, K. (2002). Social sciences research in Nepal. Economic and Political Weekly, 37(35), 3631-3643.

Haushofer, J. (2016). CV of failures. Retrieved from https://www.princeton.edu/ joha/Johann es_Haushofer_CV_of_Failures.pdf

Hironimus-Wendt, R. J., \& Wallace, L. E. (2009). The sociological imagination and social responsibility. Teaching Sociology, 37(1), 76-88.

Jessor, R. (1996). Ethnographic methods in contemporary perspective. In R. Jessor, A. Colby, \& R. A. Shweder (Eds.), Ethnography and human development:
Context and meaning in social inquiry (pp. 3-14). Chicago, IL: The University of Chicago Press.

Little, W. (2013). Introduction to sociology (1st Canadian ed.). Houston, TX: Rice University. OpenStax College, Rice University.

Mills, C. W. (1959). The sociological imagination. New York, NY: Oxford University Press.

Ministry of Education. (2008). Approaches to social inquiry: Building conceptual understandings in the social sciences. Wellington, New Zealand: Learning Media.

Parajuli, M. N. (2014). Realizing the existence of multiple forms of knowledge: A strategy towards seeing education for rural transformation. Journal of Education and Research, 4(2), 102-117.

Pyyhtinen, O. (2016). More-than-human sociology: A new sociological imagination. Basingstoke, England: Palgrave Macmillan.

Shildrick, T., \& Rucell, J. (2015). Sociological perspectives on poverty (JRF Report). York, England: Joseph Rowntree Foundation.

Soviet Sociology. (1988). Sociology in the context of the revolutionary restructuring of society. Soviet Sociology, 27(1), 7-19.

Subedi, M., \& Uprety, D. (2014). The state of sociology and anthropology: Teaching and research in Nepal. Kathmandu, Nepal: Martin Chautari. Yumatle, C. (2015). Pluralism. In M. T. Gibbons (Ed.), The encyclopedia of political thought (pp. 1-19). Hoboken, NJ: John Wiley \& Sons. 